
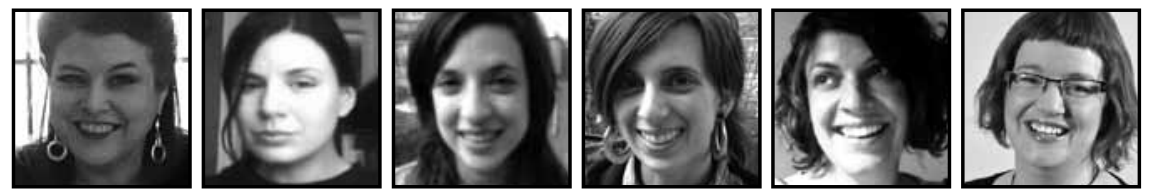

\title{
The Sense Project: An Innovative Model for Sexualities Education Partnerships Between Community-Based Educators and Schools
}

\author{
Lisa M. Trimble, Christina Foisy, Nikki MacMillan, Jos Porter, \\ Channing Rodman, \& Marlo Turner Ritchie
}

\section{ABSTRACT}

Significant changes in the way sexual health curricula would be imagined and taught occurred after the 2005 educational reforms were implemented in Quebec. Based on data collected over five years of program evaluations and interviews with community-based educators and teachers, we examine the innovative sexual health education model of the "Sense Project," developed by Head \& Hands / À Deux Mains in Montreal, and the overwhelmingly positive youth response to our program in schools and in other community youth organizations. Here we discuss some of the challenges, possibilities, and strategies involved with establishing partnerships between schools and community-based sexualities educators.

\section{Situating "Normal”}

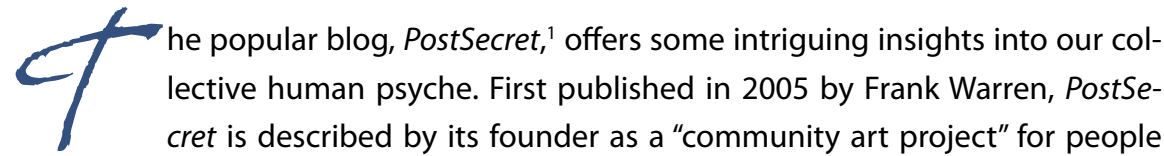
to share their secrets, the things they wonder about, and their innermost hopes and fears on an anonymous postcard. It has become a social phenomenon, with hundreds of thousands of individuals sending in their secret thoughts and worries in hopes that it will be posted on the Internet, and with millions of people connecting with others across the world on the basis of their shared human experiences. Perhaps not surprisingly, most of these shared glimpses into the lives of others offer a little window of 
insight into the ways the joys and tribulations of love, sexualities, relationships, and the body are experienced by the contributors. In just over seven years, the blog has garnered over a half billion hits (despite remaining free of advertising revenue), several books, and hundreds of consistently sold-out speaking tours during which PostSecret communities and forums meet and share their stories with one another. These micro-narratives resonate powerfully with us not only because they are common to the human condition, but also, we believe, because there are relatively few spheres to engage in meaningful conversation about what it means to be a sexual person in the bodies we live within and the social contexts we negotiate our experiences through. We are not afforded many opportunities to situate our sexual and romantic selves in relation to "normal." Chances to engage in authentic dialogue around our fears, pleasures, and desires are often few and fleeting, which makes the images and text on the PostSecret blog have such profound meaning for so many.

For youth, there are even fewer spaces where their questions of identities and sexualities can be explored in ways that speak to their experiences and questions in real and relevant ways. Too often, conversations about youth sexual subjectivity are filtered through conflicting discourses competing for the same cultural spaces. It can be difficult to sort out messages of moralist perspectives framing sex in binary terms of right and wrong (Irvine, 2002), or representations of heteronormative power dynamics and the ways they regulate and construct social understandings of gender (Johansson, 2007). Surprisingly, despite advances in teaching and learning scholarship, many students today are still taught about sexual health in very instrumentalist ways that frame sex as being primarily a function of biology and anatomy (BayCheng, 2003; Morris, 2005; Trimble, 2011). Taken individually, each of these narratives represents only a fragmented part of the possibilities of what meaningful conversations about sexualities could be and often has little to do with the experience and emotions of "real sex." As Tisdale (1994) observed,

The sex that is presented to us in everyday culture feels strange to me; its images are fragments, lifeless, removed from normal experience. Real sex, the sex in our cells and in the space between our neurons, leaks out... and gets into things, and stains our vision and colours our lives. (p. 2)

Youth are afforded very few opportunities to frankly and holistically discuss their sexual experiences of pleasure, desire, worry, and fascination in the way Tisdale describes. Fortunately, those who are looking for sexual health information have some excellent online communities to turn to. Although many excellent Internet resources are available, there are some exceptional spaces where young people can access sexual and 
relationship knowledge online. One of these is Scarleteen: Sex education for the real world. ${ }^{2}$ Scarleteen offers youth an inclusive, progressive, and comprehensive space to ask for advice, access information, and engage in discussion. Another accessible and interesting site is Sex Etc., ${ }^{3}$ a youth authored and edited online sex education magazine based in the United States. In Canada, the Native Youth Sexual Health Network is an activist group for and by indigenous youth who organize around issues of aboriginal sexual health, reproductive rights, and social justice. The site Sexualityandu ${ }^{5}$ is maintained by the Society of Obstetricians and Gynaecologists of Canada (SOGC) and offers a wealth of sexual and reproductive health information for both youth and sexualities educators. In addition, there are many dynamic, activist, youth empowerment organizations and programs which offer support for LGBTQ young people in Canada. A few of note (and by no means is this a comprehensive list) include: Camp fYrefly $^{6}$ in Edmonton; the 519 Church Street Community Centre ${ }^{7}$ and SOY (Supporting Our Youth), ${ }^{8}$ both in Toronto; Project $10^{9}$ and Head \& Hands ${ }^{10}$ in Montreal; and Youth Project ${ }^{11}$ in Halifax.

Many non-formal youth-oriented spaces are places young people can go to for conversations of youth sexual subjectivity, risk, pleasure, emotions, and identities. These same discussions can be challenging ones for young people to initiate in formal learning situations, however. Without a space in their schooling to wonder through their questions and to position themselves in relation to the broad spectrum of what "normal" can mean, young people are often left to their own devices to negotiate meaning and understanding about sexualities. In schools, the sexual health curriculum is often sanitized of any trace of anything interesting or relevant to the lives of youth. The "real sex"Tisdale is referring to involves engaging with what Allen (2005) calls the "erotic discourses" which are usually too infused with cultural charge for many educators to feel comfortable talking about.

\section{Sex Education After the Educational Reform in Quebec}

Educational reforms implemented in Quebec schools in 2005 resulted in already diminished opportunities for youth to engage in dialogue around healthy sexualities in their schools becoming almost non-existent ones. In the new reform, teachers were told by the Ministry to infuse their pedagogy with references to sexualities, sexually transmitted diseases, and orientations. The Ministry noted that these conversations could take place across the curriculum, for example these discussions could be connected to English, mathematics, science, and ethics classes. Unfortunately, this was a suggestion to educators, not a mandate. Teachers were given neither resources nor instruction on ways to support teaching about sexual health across 
the curriculum. Without sexual health pedagogy being assured in the formal curriculum, very few teachers had the necessary confidence in their own expertise in sexual and reproductive health to ensure it was included in their teaching. The implication for students was that sex education was effectively eliminated from the instruction given in most Quebec schools. Not surprisingly, the years following this decision saw a steady rise in most sexually transmitted infections in the province (PHAC, 2010), and was part of an ongoing and concerning trend of an emergent population of Canadian youth who seemingly know less about their own sexual health than students had in previous decades (Council of Education Ministers of Canada, 2003).

Staff and volunteers of Montreal non-profit youth organization Head \& Hands / À Deux Mains ${ }^{12}$ expressed alarm at this shift in educational priorities and deep concern about what the resulting implications would be for youth sexual health in the region. For more than forty years, our organization has been providing a wide range of social services for Montreal youth, offering a wide variety of ways to support and empower young people. Head \& Hands is one of the only non-profits born of the free clinic movement of the 1970s to still be working with youth, and our founding principles remain essentially the same. We offer a diverse range of services to meet the needs of youth, from legal advising to counselling, food banks, employment services, medical clinics, and street support, as well as groups for young mothers and for youth new to Canada. Working with young people aged 12-25, Head \& Hands is one of the most established and well-respected youth non-profit organizations in the province. We mobilized and conducted a needs assessment involving a series of focus groups to dialogue with local youth about their sexual health concerns and how we could best address them. From these conversations and research, the Sense Project, an inclusive and comprehensive sex education program, was born.

\section{The Sense Project}

The authors were involved in various capacities with the Sense Project, including: fund-raiser, health educators, program developer, a university researcher, and the Executive Director of the parent organization, Head \& Hands. We will briefly contextualize here some of our processes and experiences with creating the Sense Project and discuss the findings of the data collecting during five years of program evaluations. The Sense Project was entirely conceptualized by youth, who created it with the guidance of staff. During every step of the process, youth have been involved in the research, design, illustration, and implementation of the program. After every workshop and training session, the feedback of youth involved as peer educators, workshop facilitators, and workshop participants has shaped the way the program 
has evolved and grown. There have been similar sexual and relationship health projects created by youth for youth prior to the development of the Sense Project, most notably The little black book for girlz: A book on healthy sexuality (St. Stephen's Community House, 2006) and the follow-up publication, The little black book for guys: Guys talk about sex (St. Stephen's Community House, 2009). These are superb resources, and a testament to the incredible talent, imagination, and research capabilities youth can bring to a project in which they invest their passions and energies.

\section{Program Evaluation}

Typically, the program evaluation process with non-profit programs involves triangulation of data from several sources, including key stakeholders and the agency's own documentation. In the case of the Sense Project, the data included: (i) surveys from youth who participated in the workshops, (ii) surveys from youth who participated as peer educators, and (iii) weekly evaluations from the training sessions for workshop facilitators assessing the quality of their training and the issues covered. Surveys have a variety of questions to rate on a Likert scale, with possible responses ranging from "Strongly Disagree" to "Strongly Agree," and are all anonymous. Several questions are left open-ended so that youth can express their responses in their own words. Surveys are compiled by volunteers and staff in the organization, coded for emerging themes, and the data is analyzed to consider the implications for the next year's program. The staff members at Head \& Hands are deeply committed to ensuring the program is meeting the needs and expectations of youth in the region, and implement changes when youth collectively make suggestions about ways they could improve the Sense Project experience. Since the Sense Project came to life under the direction of youth advocacy organization Head \& Hands in 2006, 3734 youth have taken part in the workshops and completed surveys to give feedback on the program. The youth workshop participants are typically between 13 and 16 years old, and represent a diversity of ethnicities, class backgrounds, genders, and sexual orientations.

\section{Challenges}

One of the challenges with the program's inception involved getting the workshops into schools. School boards were reluctant to introduce the program en masse, and the resources of the new program would have been stretched beyond the staff and volunteer capacity if they had. Several private schools signed on, as well as some alternative outreach schools for youth excluded from or disenfranchised with the mainstream system. These schools have continued to work with Sense throughout 
the years. In addition, Sense also facilitates the workshops with several local youth organizations, to expand its reach beyond students currently enrolled in schools. As the program has continued to expand and be more visible in the media, teachers, school nurses, and guidance counsellors now contact Sense directly to request the workshops for their schools. Finding class time for the workshops is sometimes difficult for teachers; although the workshops only require three one-hour sessions, finding creative ways to move class instruction around is sometimes a challenge. An integral part of Sense workshops means creating a safe space for youth to openly discuss their ideas and questions, which means that we ask teachers to leave their classroom during the sessions. Teachers are very supportive of their students having access to sexual health information, but are sometimes concerned about leaving the room and some would prefer to be involved with the workshops. However, usually once we explain why we prefer to engage with the students in this way, they understand that their students may be uncomfortable with teachers being present when they discuss sexual behaviours and questions.

\section{Successes}

Although there are many factors that contribute to the success of any initiative, central to the way we imagine and bring programs to life are a few simple but powerful tenets that inform every step of our process. Five of these principles are explored here: (i) staying true to the organization's mandate and values; (ii) listening to the voices of youth; (iii) involving youth in facilitating the program; (iv) making learning fun and relevant; and (v) generating community awareness and support.

\section{Tenet 1: Staying true to the organization's mandate and values.}

Working with youth for more than four decades means that our organization has collectively developed some important insights into what works in our nonformal education practices with Montreal youth. Our approach is "preventative, inclusive, non-judgmental and holistic" (Head \& Hands / À Deux Mains, 2011). One of our core values as an agency is to provide youth the information and resources they need to make informed, safe, and aware choices about their own lives. By doing so, we consider ensuring access to knowledge and resources a vital act of political and personal empowerment of youth, and all of our programs must stay true to these values.

In keeping with our critical youth empowerment model that promotes supporting the development of youth criticality and agency, the Sense Project utilizes a harm reduction model in its sexualities pedagogy. Harm-reductionist teaching, in the context of sexual health learning, seeks to create awareness of safer sex strategies 
and relationship choices that are available to people to minimize physical or emotional harms that sexually active people potentially face. Typically, harm-reductionist approaches in sexual health education focus on STI prevention and identification, developing negotiation strategies (for example, teaching youth that it is their right to insist that a partner wear a condom or helping them to develop responses to a partner's unwelcomed coercive sexual behaviours, or to negotiate their own pleasures and desires in their sexual relationships). Harm reduction is a philosophy personified by (i) a non-judgmental and comprehensive approach to making sexual knowing available, (ii) meeting people "where they are" and "which aim to provide and/ or enhance skills, knowledge, resources and support that people need to live safer, healthier lives" (Government and Public Awareness Task Group of NPNU Consortium, 2000 , p. 5). Harm reduction attempts to build on strengths and increase the knowledge and confidence of the people involved, while validating their experiences and personhood.

Access to comprehensive information and local resources is central to the principles of harm-reduction, and is foundational to the mission and mandate of Head \& Hands. The Sense Project was conceptualized as a partnership between community-based educators from Head \& Hands and local schools. In addition to training volunteer facilitators on a wide variety of sexual health subjects (including such topics as: STIs, legal implications such as the age of consent, how youth can find and access local sexual health resources, and anti-oppressive pedagogical strategies), we also invited youth to become involved as peer educators. Youth responded with enthusiasm, and not only attended a series of workshops where they learned about a variety of topics and resources related to sexual and emotional health, but also extensively researched and co-authored and created all the graphics for a comprehensive 255-page Peer Educator's Resource Manual'13 (Head \& Hands / À Deux Mains, 2007) with the supervision of the Head \& Hands health educator. Peer educators and volunteer workshop facilitators found their affiliation with the Sense Project so rewarding that many of them returned in following years to complete the training again and to be involved in this dynamic non-formal teaching experience. Schools who are interested in having the community-based educators teach their students contact Head \& Hands, who send volunteer facilitators to teach three one-hour long workshops for a nominal fee. On average, between 700 and 900 Montreal youth per year have been involved as workshop participants since the program's inception. After focusing primarily on schools during their first year, the Sense Project staff and volunteers expanded their reach to offer their sexual health workshops to other youth-involved non-profit organizations. 


\section{Tenet 2: Listening to the voices of youth.}

Data collected by Head \& Hands in program evaluation reports clearly show that youth response to their workshops has been overwhelmingly positive, with 90-95\% annually self-reporting in surveys that the information they learned in the workshops would be useful in their own lives and that the youth wanted considerably more sexualities education than they were currently receiving. Comments offered by youth participants describe a meaningful and comprehensive learning experience, with many wanting regular workshops to be offered in their schools focusing on topics of sexualities and relationships. Overwhelmingly, the message the youth sent was that they wanted considerably more access to sexual health education in their schools. Most importantly, they asked for a literal and discursive space where they could safely wonder through their own worries, questions, and concerns, without being judged.

I think you guys should do workshops all year, throughout the year...like every week or once or twice a month throughout the whole year. (Female student, grade 9)

Instead of just saying things, or telling us a basic overview of things they wanted to, they let us speak about what we were interested in. It was very good. (Male student, grade 10)

Some students also appreciated the freedom to explore personal issues with the relative anonymity offered by learning sexual health information from someone they didn't have a pre-existing relationship with.

I feel sex education is much easier with someone you don't know because they're not around to compare or say anything about you and there's more confidentiality. If it was a teacher, they would probably look at you different, like, 'this person does this...this person does that'. (Female student, grade 10)

Other scholarship has shown that both students and teachers echo their preference for sexual health curricula to be taught by an outside expert (Westwood \& Mullan, 2007). Even if the relationship with teachers is one with strong elements of trust between students and teachers, the educators often feel that gaps exist in their knowing about sexual health issues and that they may lack the necessary expertise to navigate the many social, political, and cultural nuances involved in teaching about sexualities. This perception is not a surprising one, as a recent survey of all Canadian 
universities offering teacher education programs found that at the time of press of this article, none of them offered a mandatory course to help new teachers develop the knowledge and skills to teach sexual health (Trimble, 2011), although some programs for teacher candidates may be in the developmental stages. ${ }^{14}$

All of the programs developed by Head \& Hands, including the Sense Project, are framed from a critical, social justice perspective that takes into account the intersectionality of social and cultural contexts related to power, including (among others) considerations of race, class, gender, language, sexual orientation, age, and ability. True to the ethos and vision we work through, decisions about the program are made collaboratively by staff. Staff and volunteers engage in an ongoing "unlearning" process (Britzman, 1998; Kumashiro, 2000) and question and challenge their own assumptions about who youth are and what they need. Instead, and crucial to the success of this program, they listen to the voices of youth themselves. In this paradigm, youth define themselves, name their concerns and the organization listens to and tries to respond to youth-identified issues.

I think the most important thing to me is the idea that the youth know themselves best. They know their identities... Even if they're questioning themselves. They know that about themselves. You don't. I think the most important thing is to trust that they know themselves and their experiences and how they're feeling, what they're thinking about themselves and what they do and don't know, and to just let them set the pace. (R.M., Sense Project volunteer workshop facilitator)

You need to be pretty grounded in [what] youth's actual needs are, not assuming what their needs are, or addressing needs if they're not actually there, if that makes any sense. I think that's one of the really great things about Head \& Hands that really equips us to do that. We have such holistic programming. The Sense Project fits into a holistic health centre, so for Sense it was a natural growth because we have a medical clinic for youth, we have a teen drop-in centre where there is basketball and recreational activities. We have so many places and spaces to get familiar with what their actual concerns are. I'm doing some work at the clinic right now, and it's invaluable to me to hear about why youth want to get tested and what their actual worries are. (Nikki, staff health educator)

Not only are youth consulted throughout the initial development and planning stages of the program, but the evaluation feedback from youth workshop 
participants, volunteer facilitators, and peer educators is carefully reviewed by staff and external researchers at the end of the school year. The most recent evaluations (2011) show a 95\% youth approval rate in almost all of the categories we asked youth to give us their feedback on. We are keenly aware, however, that these conversations about vision, action, and process need to be continually in dialogue with the ways youth relate to and interpret their experiences with the program. Revisions to the curricula, activities, or training process are made annually to refine the program based on the youth participants' recommendations and suggestions.

\section{Tenet 3: Involving youth in facilitating the program.}

In addition to consulting young people in the design of the Sense Project, we recruit youth themselves to be facilitators of the workshops because we believe that peer education is an important aspect of why this program works so well. All of the facilitators are under 26 years of age, and have completed training workshops prior to being partnered with one another and teaching the program in schools. We recognize that peer education is not uncontroversial in some academic circles, for example, Turner and Shepard (1998) called it "a method in search of a theory" and concluded that while some peer education programs could claim excellent results, the empirical evidence did not exist to unilaterally declare this method to be superior to non-peer directed learning. Neither are we making this claim; peer education is not necessarily empowering in and of itself. Youth are surrounded with the same racist, gendered, and classed cultural stories as the rest of the world, and youth-generated knowledge may reproduce the same oppressive themes. Helping youth to insert their own interpretations and experiences into these stories and generate new meanings and understandings, however, is crucial to establishing a program of critical, empowering peer education.

We contend that the empowerment aspect of youth peer education can be fully recognized when youth work together to be active producers of knowledge and learn how to negotiate with their own agency and ability to influence personal and social change. We work with young people to help develop their critical capacity to challenge disempowering or oppressive narratives and to imagine new and better ways of being. From our perspective, peer education that is supported with dialogic, critical, and reflective pedagogy can be a transformative teaching strategy. In other words, we suggest that when any educational method is not rooted in theory it will be ineffectual in the long term; without theory to think through how the aims of education are connected to the processes of teaching and learning, it is difficult to build bridges across praxis and meaning. Our peer education programs are grounded in critical, constructivist social theory (Kincheloe, 2008), developed within the principles 
and paradigms of harm reduction philosophies (Government and Public Awareness Task Group of NPNU Consortium, 2000; Lenton \& Single, 1998), and additionally theorized through the lenses of critical youth empowerment models (Jennings, ParraMedina, Hilfinger Messias, \& McLouglin, 2006).

\section{Tenet 4: Making learning fun and relevant.}

Many youth workers have developed an almost intuitive pedagogical expertise when it comes to recognizing the kinds of teaching strategies that work with youth, primarily because when young people are choosing to engage in non-formal education it must be interesting and motivating enough for them to continue to make the choice to do so. As a result, non-formal educators have developed some creative and highly effective pedagogical strategies in their youth programs, incorporating the ideas of progressive learner-centered theories (i.e., Dewey, 1938; Kolb, 1984) with a strong emphasis on the experiential. Experiential learning involves the whole person (senses, intellect, and emotion), and is shaped by the social and cultural contexts we live within (Boud, Cohen, \& Walker, 1993). In our own pedagogical praxis, we develop our learning activities with youth around those ideas, plus the other foundations of experiential learning, including: building on what the youth already know, reflecting on how some knowing connects to or contradicts other knowing, and that learning takes place through a series of short, defined learning events such as games, reflective activities, or role-playing (Andresen, Boud, \& Cohen, 2000). One of the most popular games we play with youth during the workshops is "Sexual Health Jeopardy," where participants compete to share their knowledge about sexual and reproductive health. In the "Alphabet Game," we ask youth to go through the alphabet and come up with a reason for every letter why they might want to abstain from sexual activities, and then to do the same exercise listing all the reasons why they might choose to engage with them.

Our workshops are learner-centered, involving curricula meaningful and relevant to the lived experiences of young people. In our experience, youth respond most enthusiastically when active learning is coupled with plenty of opportunities for interaction. Whenever possible, we encourage tactile learning through handling of materials such as condoms and lubricant so that youth can demystify some of the experience of using them. We allow a lot of space for discussion, and answer all questions youth ask because we believe the process of learning is both dialogic and experiential. By encouraging young people to ask the questions that matter most to them, and have them answered in the most comprehensive and authentic ways we know how, we are helping them to engage with sexual health knowledge, manage their risk in informed and aware ways and develop a strong sense of their own agency. 


\section{Tenet 5: Generating community awareness and support.}

We identified two priorities early in the development process of the Sense Project that would have a profound impact on how sustainable this program was over the long term. First, we needed to have ongoing connections with other non-profit youth organizations. Part of our ethos as a community youth organization means being involved in "deep citizenship," which Clarke defined as "care of self, care of others and care of the world" (1996, p. 18). One of the ways we interpret contributing to community well-being as a non-profit group means sharing resources, strategies, and expertise with other organizations, and benefitting from their knowledge and experiences as well. Throughout the course of the program to date, we have partnered with three universities and several other local non-profit groups who brought specialized knowledge to the training sessions about topics such as anti-oppressive teaching, sexual assault, HIV and AIDS, and transgender communities, among others. Both the youth peer education training and the volunteer workshop facilitator training involved workshops offered by our community partners, as well as bringing awareness to the volunteers about additional resources they could refer youth to or engage with for their own purposes.

Our second priority to ensure sustainability of the Sense Project was to try and secure ongoing sources of funding from the community, so that the program is not entirely dependent on funds from federal, provincial, or foundational grants. As recent politically motivated events with women's organizations such as Planned Parenthood in the United States have demonstrated, ${ }^{15}$ when funding is tied to organizations that do not necessarily share the same core values and philosophies, entire programs can be jeopardized when ideological or political shifts occur. The support from the community for the Sense Project has been exceptional, with funds being raised through diverse sources including (but not limited to): a monthly queer dance party, a summer volleyball tournament between local bars and clubs, various college and university fundraisers, and participation in sponsored walks such as the local HIV and AIDS awareness fundraising walk.

Discussions of youth sexualities are charged with cultural stories, conflicting moralist ideas, and political ideologies that can have profound implications for funding tied to external sources. Giroux (1998) observed that the bodies and sexualities of young people are often the primary sites of political representation and conflict in the culture wars, something we have seen play out in public discourses many times. As much as possible, we try to ensure the long-term sustainability of the Sense Project by having diversified funding sources with deep and varied webs of community support. 


\section{Rethinking the Formal/Non-formal Divide in Education}

Non-formal education strategies have proven to be highly effective with youth, particularly within the educational contexts of some developing nations and adult learners. Ironically, it may be the fact that it is so successful with marginalized groups that continues the marginalization of non-formal education itself. Until educators can see the strategies of non-formal learning holistically, as a part of the whole spectrum of possibilities to support good teaching and learning, it may continue to be thought of as being outside of or subordinate to formal education. Brennan (1997) summarized this neatly when he suggested that there were essentially three ways of understanding non-formal education: (i) as a complement to achieve the goals that formal education may have failed in (such as high school drop-outs and alternative schools); (ii) as an alternative to formal education (i.e., types of aboriginal knowledge) and as a supplement, especially for developing nations (cited in Taylor, 2006, p. 294, italics original). We see these distinctions as being potential obstacles to students engaging some opportunities for rich, meaningful, and in-depth learning. We envision a future in schooling where the bridges between teaching strategies labelled as "non-formal" or "formal" become more blurred, and the emphasis is instead on the pedagogical processes and contexts that support and promote good learning. We are not the only ones with this vision; Torres (2001) makes the argument that there are important conceptual shifts currently taking place in how schooling is being imagined that are directly linked to teaching strategies usually associated with non-formal education. She contends that some of the defining features of non-formal education, including "flexibility, school-community linkages, openness and responsiveness to the needs and possibilities of the learners and to specific contexts and culture" are some of the tenets of good teaching in general, and should not only be relegated to the non-formal learning. Indeed, as she notes in the current climate of school reforms, "Acknowledging diversity, demands-driven, needs assessment, ownership, family and community participation, decentralization, school autonomy, accountability, and transparency have become mainstream thinking and attributes of good practice" (p. 5). We agree with this assessment, and have seen how remarkable the outcomes can be when community-based, non-formal educators and schools work together to provide a sexual health education that is comprehensive, student-centered, meaningful, and relevant. 


\section{Acknowledgments}

The authors would like to acknowledge several individuals who also envisioned and brought the Sense Project into being, and without whom, none of this exciting work would have been possible, including: Allyson-Joy Flynn, Kathleen KampeasRittenhouse, and Adriana Trujillo. Ongoing funding for the project is also being sustained by the work of Sarah Odell and the many volunteers who give their time and energies to ensuring youth of Montreal have access to comprehensive, nonjudgmental, and inclusive sexualities education.

\section{Notes}

1. PostSecret can be found at www.postsecret.com.

2. See www.scarleteen.com.

3. See www.sexetc.org.

4. See www.nativeyouthsexualhealth.com.

5. See www.sexualityandu.ca.

6. See www.fyrefly.ualberta.ca.

7. See www.the519.org.

8. See www.soytoronto.org.

9. See www.P10.qc.ca.

10. See www.Headandhands.ca.

11. See www.youthproject.ns.ca.

12. References to Head \& Hands / À Deux Mains will be shortened to Head \& Hands throughout this article. 
13. We are proud of the great work the youth did with this manual, and are pleased to offer it as a free, downloadable PDF, which can be accessed here: http://www. mediafire.com/?et1mxxgmz4g. Print copies are available through Head \& Hands for a donation.

14. Concordia University in Montreal, we are happy to report, is in the process of developing and implementing such a required course for their student teachers.

15. At the time of press, Planned Parenthood has been under attack by the conservative right in the U.S. with numerous attempts being made at both the federal and state levels to de-fund them entirely. Some lobbyists are pressuring philanthropist organizations to disqualify Planned Parenthood from being eligible to apply for grants.

\section{References}

Allen, L. (2005). Sexual subjects: Young people, sexuality and education. New York: Palgrave Macmillan.

Andresen, L., Boud, D., \& Cohen, R. (2000). Experience-based learning: Contemporary issues. In G. Foley (Ed.), Understanding adult education and training (pp. 225239). Sydney, AU: Allen \& Unwin.

Bay-Cheng, L. (2003). The trouble of teen sex: The construction of adolescent sexuality through school based sexuality education. Sex Education, 3(1), 61-74.

Boud, D., Cohen, R., \& Walker, D. (Eds.). (1993). Using experience for learning. Buckingham, UK: Society for Research into Higher Education and Open University Press.

Britzman, D. P. (1998). Lost subjects, contested objects: Toward a psychoanalytic inquiry of learning. Albany: State University of New York Press.

Clarke, P. B. (1996). Deep citizenship. London: Pluto Press.

Council of Ministers of Education of Canada. (2003). Canadian youth, sexual health and AIDS study: Factors influencing the sexual health of Canadian youth. Retrieved
March 22, 2003, from http://www.cmec. ca/Publications/Lists/Publications/ Attachments/180/CYSHHAS_2002_ EN.pdf

Dewey, J. (1938). Experience and education. New York: Collier Books.

Giroux, H. (1998). Teenage sexuality, body politics and the pedagogy of display. In J. S. Epstein (Ed.), Youth culture: Identity in a postmodern world (pp. 24-55). Malden, MA: Blackwell.

Government and Public Awareness Task Group of NPNU Consortium. (2000). Harm reduction information kit: For professionals working with at-risk populations. Retrieved August 19, 2011, from http:// www.harmreductionnetwork.mb.ca/ docs/infokit.pdf

Head \& Hands / À Deux Mains. (2007). The Sense Project: Peer educator training manual. Montreal, QC: Head \& Hands / À Deux Mains.

Head \& Hands / À Deux Mains. (2011). Vision and mission. Retrieved January 18, 2011, from http://headandhands.ca/about-us/ 
Irvine, J. M. (2002). Talk about sex: The battles over sex education in the United States. Berkeley: University of California Press.

Jennings, L. B., Parra-Medina, D. M., Hilfinger Messias, D. K., \& McLoughlin, K. (2006). Toward a critical social theory of youth empowerment. Journal of Community Practice, 14(1/2), 31-55.

Johansson, T. (2007). The transformation of sexuality: Gender and identity in contemporary youth culture. Burlington, VT: Ashgate Publishing.

Kincheloe, J. L. (2008). Critical constructivism. New York: Peter Lang.

Kolb, D. (1984). Experiential learning: Experience as the source of learning and development. Englewood Cliffs, NJ: Prentice Hall.

Kumashiro, K. K. (2000). Toward a theory of anti-oppressive education. Review of Educational Research, 70(1), 25-53.

Lenton, S., \& Single, E. (1998). The definition of harm reduction. Drug and Alcohol Review, 17(2), 213-220.

Morris, R. W. (2005). Research and evaluation in sexuality education: An allegorical exploration of complexities and possibilities. Sex Education, 5(4), 405-422.

Public Heath Agency of Canada. (2010). Reported cases of notifiable STI from January 1 to June 30 and January 1 to June 30, 2009. Ottawa, ON: Centre for Communicable Diseases and Infection Control, Public Health Agency of Canada.
St. Stephen's Community House. (2006). The little black book for girlz: A book on healthy sexuality. Toronto, ON: Annick Press.

St. Stephen's Community House. (2009). The little black book for guys: Guys talk about sex. Toronto, ON: Annick Press.

Taylor, E. W. (2006). Making meaning of local non-formal education: Practitioner's perspective. Adult Education Quarterly, 56(4), 291-307.

Tisdale, S. (1994). Talk dirty to me: An intimate philosophy of sexuality. New York: Doubleday.

Torres, R.-M. (2001). Mainstreaming NFE: Moving from the margin and going to scale. Paper presented at the ADEA Biennale, Arusha, Tanzania.

Trimble, L. M. (2011). Teaching and learning sexual health at the end of modernity: Exploring postmodern pedagogical tensions and possibilities with students, teachers and community-based educators. (Doctoral dissertation), McGill University, Montreal, QC.

Turner, G., \& Shepherd, J. (1999). A method in search of a theory: peer education and health promotion. Health Education Research, 14(2), 235-247.

Westwood, J., \& Mullan, B. (2007). Knowledge and attitudes of secondary school teachers regarding sexual health education in England. Sex Education, 7(2), 468-474. 


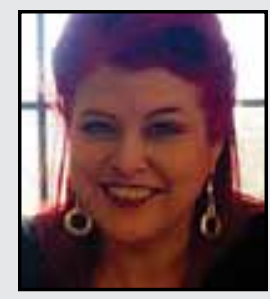

Lisa M. Trimble (Ph.D.) teaches social justice, critical theory, media, and service learning courses in the Department of Integrated Studies in the Faculty of Education at McGill University in Montreal. She is also an education consultant who specializes in program evaluation research for post-secondary institutions and non-profit organizations. Her current research explores the ways schools and non-formal educators can meet the needs of marginalized and excluded youth by identifying, developing, and building on community strengths and capacities.

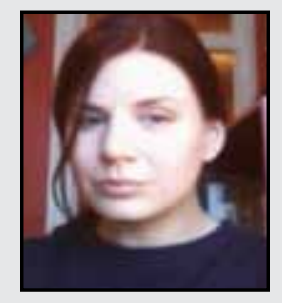

Christina Foisy is a PhD student in Humanities at York University. Her research considers autobiographical narratives by women who underwent electroconvulsive therapy and how they represent a life re-routed by shock. Her poetry / sound art has appeared at the Women Made Gallery and the Journal of Research on Mothering.

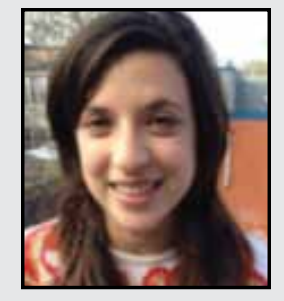

Nikki MacMillan is the Health Educator at Head \& Hands, a Montreal community organization dedicated to youth empowerment, health, and well-being. She coordinates the Sense Project, Head \& Hands' peer-based sex education program, and works with youth and volunteers to provide sexual health education at a grassroots level in local high schools, community centres, drop-ins, and wherever young people can be found. She holds a Bachelor's Degree in International Development Studies from York University and previously worked in arts education for social change at the Children's Peace Theatre in Toronto. 


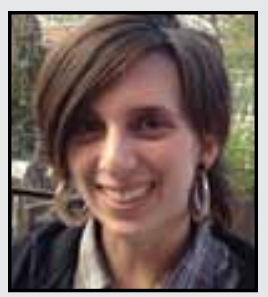

Jos Porter is a front-line community worker, educator, and activist based in Montreal. She coordinates the health services at Head \& Hands, a non-profit grassroots organization dedicated to youth empowerment. With a degree in Literature and Women's Studies from McGill University and a background in social justice activism, she works to promote access to quality healthcare for all, as well as sexual/reproductive health awareness, dialogue, positivity, and well-being.

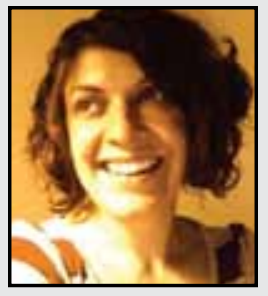

Channing Rodman has 10 years of experience in research, communications, and development for both start-ups and non-profit organizations. As part of the initiating team for the Sense Project, she worked as the funding and program developer. Currently, she works as a social media strategist in Vancouver, B.C.

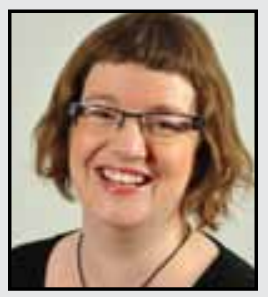

Marlo Turner Ritchie is a collaborative leader for community development with fifteen years experience working in non-profit, education, and research settings in Vancouver and Montreal. She is the Lead Coordinator at L'Abri en Ville, an organization that provides a stable and fulfilling environment for persons with a mental illness through safe, affordable housing and inclusion in a supportive community. She has been the Executive Director for Head \& Hands / À Deux Mains, and Coordinator at Project 10; both are dynamic, bilingual, youth empowerment organizations. She has a Liberal Arts degree from McGill University and is an avid student of life.

\section{LINK TO:}

http://www.headandhands.ca 